\title{
Measuring outcomes within inpatient child and adolescent mental health services: an evaluation of the Recovery Questionnaire for Young People
} DOI:

10.1111/camh. 12337

\section{Document Version \\ Accepted author manuscript}

Link to publication record in Manchester Research Explorer

Citation for published version (APA):

Bentley, N., Bucci, S., \& Hartley, S. (2019). Measuring outcomes within inpatient child and adolescent mental health services: an evaluation of the Recovery Questionnaire for Young People. Child and Adolescent Mental Health. https://doi.org/10.1111/camh.12337

\section{Published in:}

Child and Adolescent Mental Health

\section{Citing this paper}

Please note that where the full-text provided on Manchester Research Explorer is the Author Accepted Manuscript or Proof version this may differ from the final Published version. If citing, it is advised that you check and use the publisher's definitive version.

\section{General rights}

Copyright and moral rights for the publications made accessible in the Research Explorer are retained by the authors and/or other copyright owners and it is a condition of accessing publications that users recognise and abide by the legal requirements associated with these rights.

\section{Takedown policy}

If you believe that this document breaches copyright please refer to the University of Manchester's Takedown Procedures [http://man.ac.uk/04Y6Bo] or contact uml.scholarlycommunications@manchester.ac.uk providing relevant details, so we can investigate your claim.

\section{OPEN ACCESS}




\section{Child and Adolescent Mental Health}

\section{Measuring outcomes within inpatient child and adolescent mental health services: an evaluation of the Recovery Questionnaire for Young People}

\begin{tabular}{|c|c|}
\hline Journal: & Child and Adolescent Mental Health \\
\hline Manuscript ID & CAMH-OA-2019-0014.R3 \\
\hline Wiley - Manuscript type: & Original Article \\
\hline $\begin{array}{r}\text { Date Submitted by the } \\
\text { Author: }\end{array}$ & $n / a$ \\
\hline Complete List of Authors: & $\begin{array}{l}\text { Bentley, Natalie; University of Manchester, Division of psychology and } \\
\text { mental health } \\
\text { Bucci, Sandra; University of Manchester, Division of Psychology and } \\
\text { Mental Health } \\
\text { Hartley, Samantha; Pennine Care NHS Foundation Trust; University of } \\
\text { Manchester, Division of Psychology and Mental Health }\end{array}$ \\
\hline Key Words: & Adolescence, Outcome, Mental health \\
\hline Abstract: & $\begin{array}{l}\text { Background: The notion of personal recovery has become central to the } \\
\text { delivery of mental health services; however, no published subjective } \\
\text { recovery measure has been validated in an inpatient adolescent mental } \\
\text { health sample. We aimed to evaluate the psychometric properties of the } \\
\text { Recovery Questionnaire for Young People (ReQuest-YP) in this inpatient } \\
\text { context. } \\
\text { Methods: Both cross-sectional and longitudinal self-report data were } \\
\text { collected. The ReQuest-YP was administered to } 65 \text { adolescents ( } 11 \\
\text { males, } 52 \text { females and } 2 \text { who identified as transgender) within inpatient } \\
\text { child and adolescent mental health services (UK) along with a feedback } \\
\text { questionnaire, to assess the face validity of the measure. The young } \\
\text { person's Health of the National Outcome Scales (HoNOSCA) score, as } \\
\text { rated by clinicians in inpatient services, was also obtained to assess the } \\
\text { convergent validity of the measure. } \\
\text { Results: The results demonstrated that the ReQuest-YP demonstrated } \\
\text { excellent internal consistency (alpha } \geq .914 \text { ), test-retest reliability (ICC } \\
=.91 \text { ) and sensitivity to change (Z=-2.09). The measure did not } \\
\text { correlate with the ratings on the HoNOSCA. Feedback indicated the } \\
\text { ReQuest-YP was relevant and acceptable to young people. Suggestions } \\
\text { were made about refining some questionnaire items. } \\
\text { Conclusions: The ReQuest-YP demonstrated clinical utility as a measure } \\
\text { of subjective recovery in inpatient child and adolescent mental health } \\
\text { services. Refinement of some of the questions along with further } \\
\text { evaluation of the measure in this population is recommended. }\end{array}$ \\
\hline
\end{tabular}




\section{SCHOLARONE ${ }^{\text {M }}$ Manuscripts}


Measuring outcomes within inpatient child and adolescent mental health services: an evaluation of the Recovery Questionnaire for Young People

Natalie Bentley ${ }^{1}$

Sandra Bucci ${ }^{1}$

Samantha Hartley* 1,2

1 Division of Psychology and Mental Health, School of Health Sciences, Faculty of Biology, Medicine and Health, University of Manchester, Manchester Academic Health Sciences Centre, Manchester, UK

2 Pennine Care NHS Foundation Trust

*Author for correspondence

Dr Samantha Hartley

2nd Floor, Zochonis Building,

Brunswick Street

University of Manchester

M13 9PL.

samantha.hartley@manchester.ac.uk 


\section{Acknowledgements}

Funding for this project was provided via the Clinical Psychology Doctorate training budget of the first author. We would like to thank the clinical teams, psychology teams, service users and managers of the units involved. 


\section{Measuring outcomes within inpatient child and adolescent mental health services: an evaluation of the Recovery Questionnaire for Young People}

Running head: Measuring outcomes in inpatient CAMHS: ReQuest-YP

Natalie Bentley ${ }^{1}$

Sandra Bucci ${ }^{1}$

Samantha Hartley* 1,2

1 Division of Psychology and Mental Health, School of Health Sciences, Faculty of Biology, Medicine and Health, University of Manchester, Manchester Academic Health Sciences Centre, Manchester, UK

2 Pennine Care NHS Foundation Trust

*Author for correspondence

Dr Samantha Hartley

2nd Floor, Zochonis Building,

Brunswick Street

University of Manchester

M13 9PL.

samantha.hartley@manchester.ac.uk

\section{Ethics}

The research was approved by the North West - Greater Manchester Central Research Ethics Committee (REC reference: 17/NW/0169) and all relevant ethical guidelines were adhered to. 


\begin{abstract}
Background: The notion of personal recovery has become central to the delivery of mental health services; however, no published subjective recovery measure has been validated in an inpatient adolescent mental health sample. We aimed to evaluate the psychometric properties of the Recovery Questionnaire for Young People (ReQuestYP) in this inpatient context.
\end{abstract}

Methods: Both cross-sectional and longitudinal self-report data were collected. The ReQuest-YP was administered to 65 adolescents (11 males, 52 females and 2 who identified as transgender) within inpatient child and adolescent mental health services (UK) along with a feedback questionnaire, to assess the face validity of the measure. The young person's Health of the National Outcome Scales (HoNOSCA) score, as rated by clinicians in inpatient services, was also obtained to assess the convergent validity of the measure.

Results: The results demonstrated that the ReQuest-YP demonstrated excellent internal consistency (alpha $\geq .914)$, test-retest reliability $(\mathrm{ICC}=.91)$ and sensitivity to change $(Z=-2.09)$. The measure did not correlate with the ratings on the HoNOSCA. Feedback indicated the ReQuest-YP was relevant and acceptable to young people. Suggestions were made about refining some questionnaire items.

Conclusions: The ReQuest-YP demonstrated clinical utility as a measure of subjective recovery in inpatient child and adolescent mental health services. 
Refinement of some of the questions along with further evaluation of the measure in this population is recommended.

\section{Key words}

Adolescent; recovery; measure; inpatient; outcome; mental

\section{Practitioner points}

- The ReQuest-YP offers a potential tool for exploring, assessing and evaluating subjective or personal recovery for young people in inpatient units

- The measure is potentially reliable, valid and acceptable to service users and so clinicians may wish to consider use in these settings

- There is indication that the questionnaire is also sensitive to change in an inpatient admission context, although further work is needed

\section{Word count}

4590 


\section{$\underline{\text { Introduction }}$}

Adolescence is the peak time for mental health problems to develop, with threequarters established by age 24 and $11.5 \%$ of young people aged between $11-16$ years meeting criteria for a mental 'disorder' (Green, McGinnity, Meltzer, Ford \& Goodman, 2005). The concept of recovery is increasingly at the forefront of treatment for mental health difficulties (Slade, Amering, Farkas, Hamilton, O’Hagan, Panther, Perkins, Shepherd, Tse \&Whitley, 2014). Despite continued discussion (Davidson \&Roe, 2007), it is widely accepted that there are two parallel models of recovery, 'clinical' and 'personal' recovery. Clinical recovery emphasises a reduction in clinical symptoms, relapse prevention and risk management and the person returning to their former self (Petersen, Friis, Haxholm, Nielsen \& Wind, 2015). A related but nevertheless divergent concept is the notion of "personal recovery', which is centered around connectedness, hope and optimism about the future, identity, meaning in life and empowerment (Tew, Ramon, Slade, Bird, Melton \& Le Boutillier, 2012; Pitt, Kilbride, Nothard, Welford \& Morrison, 2007; Leamy, Bird, Le Boutillier, Williams \& Slade, 2011). In relation to young people specifically, recent changes to mental health policy in the United Kingdom (UK) have seen recovery-orientated approaches implemented in Child and Adolescent Mental Health Services (CAMHS, e.g. Wolpert, Harris, Jones, Hodges, Fuggle, James \& Fonagy, 2014; NHS England, 2015).

Measuring outcomes in mental health enables clinicians to identify treatment goals, evaluate interventions, and fuels a drive for effective service evaluation (Department of Health, 2002; NHS England, 2015). Symptom-based outcome measures have been traditionally used in CAMHS to measure the presence or absence of psychiatric symptoms and general functioning. However, Donnelly, et al. (2011) suggest that specific service user informed recovery outcome measures, 
alongside routine outcome measures, are necessary to aid a greater understanding of a young person's recovery process.

Future in Mind (NHS England, 2015) identified inpatient CAMHS as requiring a full system modification, to provide a more accessible and person-centred service for young people, with recent developments targeting alternatives to inpatient care. Young people accessing inpatient CAMHS are often those with the most complex, severe or persistent mental health problems (McDougall, Worrall, Davies Hewson, Richardson \& Cotgrove, 2008) who report feeling a loss of control and power over their care and feel disconnected from 'normal' life (Offord, Turner \& Cooper, 2006). As a result, outcome measures routinely used within community CAMHS may not fully capture the young person's experience of their inpatient stay, with most validation studies having been implemented in community contexts. Moreover, improving inpatient CAMHS relies on measuring clinically meaningful outcomes to inform change; however, high quality clinical and outcome focused research is currently lacking in these services (Garralda et al., 2008). Using a recovery-orientated approach to routine outcome measurement may provide more effective service evaluation (Future in Mind; NHS England, 2015) and the opportunity for other important aspects of young people's lives to be recognised and supported in this setting.

The ReQuest-YP (John et al., 2015) is the only known specific recovery focused outcome measure developed for use with a child and adolescent mental health population, despite a number of personal recovery measures having been validated in other settings (Shanks et al., 2013) and recent new measurement tools which take a child-centred approach (Godfrey et al., 2019). The development of the ReQuest-YP was based on young people's personal experience of mental health difficulties and their recovery journey (Simonds, Pons, Stone, Warren \& John, 2014) 
and the measure demonstrated good psychometric properties in a sample of young people accessing community mental health services (John et al., 2015). The application of this measure in assessing personal recovery in young people within inpatient mental health services is as yet unknown.

\section{Study aim and hypotheses}

This study aimed to examine the psychometric properties of the ReQuest-YP to determine whether this questionnaire is an effective measure of personal recovery within the context of inpatient CAMHS. More specifically, we proposed to assess the internal consistency, test- retest reliability, concurrent validity, sensitivity to change and acceptability of the ReQuest-YP. We hypothesised that: i) there would be a significant association between an individual's scores on the ReQuest-YP within a two-week period at $\mathrm{T} 1$ and $\mathrm{T} 2$, reflecting adequate test-retest reliability of the measure; ii) the measure would demonstrate good internal consistency, as demonstrated in a community CAMHS sample (John et al., 2015); iii) in line with findings with adults (Corrigan, Giffort, Rashid, Leary \& Okeke, 1999; Resnick, Rosenheck \& Lehman, 2004), there would be a negative correlation between scores on the clinician-rated Health of the National Outcome Scales version 5 (HoNOSCA; Gowers, Harrington, Whitton, Lelliott, Beevor, Wing, Jezzard,1999) and the ReQuest-YP; iv) there will be a significant difference between the two scores on the ReQuest-YP over time, with an individual's discharge score being higher than their score when they initially completed the ReQuest-YP. Feedback was also sought from young people about the ReQuest-YP to determine the face validity and the relevance of the measure in an inpatient CAMHS context by providing an additional 'feedback' questionnaire about the ReQuest-YP to all young people who participated. 


\section{Method}

\section{Ethics}

The research was approved by the relevant UK National Health Service (NHS) research ethics committee. Consent procedures for those under 18 were followed in line with the Health Research Authority recommendations and NHS ethics approval.

\section{Design}

The study employed a mixed-methods design. A statistical evaluation of the psychometric properties of the ReQuest-YP was undertaken, alongside a semistructured feedback questionnaire and qualitative analysis to obtain greater insight into adolescents' opinions regarding the face validity and relevance of the ReQuestYP.

\section{Participants}

Participants were young people recruited over a 7-month-period (August 2017 to March 2018) from five NHS inpatient CAMHS units in the UK. Potential participants were considered eligible if they were aged between 12 to 18 years, fluent in English, and were able to provide fully informed consent or parental consent was obtained along with young person assent. Those that did not meet these criteria were excluded from the study.

\section{Materials}

Recovery Questionnaire for Young People (ReQuest-YP; John et al., 2015). 
The ReQuest-YP (John et al., 2015) is a measure of subjective recovery developed for use with young people aged 10 to 18 . The development of the measure was informed by firsthand accounts from young people with anxiety and / or depression, about their experience of recovery (Simonds et al., 2014). The ReQuest-YP questionnaire consists of 30 items each rated on a four point Likert scale $(0=$ not at all, to $3=$ completely). John and colleagues (2015) found that the measure showed sound psychometric properties in a community sample, including high internal consistency (Cronbach's alpha $<0.89$ ). The measure correlated as expected with measures of similar constructs, including a measure of emotional and behavioural difficulties $(r=.74)$ and a measure of self-esteem $(r=.84)$. The results also revealed a strong positive correlation between child and parents reports of the young person's recovery $(r=.75)$.

\section{Feedback questionnaire}

A feedback questionnaire was developed by the authors drawing on previously developed tools (Bentley, Davies, Sellen \& Maggs, 2017) and consisted of nine questions regarding aspects of the ReQuest-YP, with Likert scale response options ranging from strongly disagree to strongly agree. The questionnaire also consisted of four open-ended questions: What, if anything, did you like about the ReQuest-YP? What, if anything, did you dislike about the ReQuest-YP? Are there any questions you think should be removed from the ReQuest-YP questionnaire? Was there anything missing from the ReQuest-YP that you think should be included? 
The HoNOSCA is a clinician rated scale for measuring emotional and behavioural problems in children and adolescents aged 3-18 and comprises 15 questions scored on a $0-4$ point rating, ranging from 'no problems' to 'severe problems'. The HoNOSCA has been shown to be acceptable for use in clinical settings and to have good sensitivity to change in an adolescent inpatient setting, with a strong positive correlation between initial and subsequent ratings evident $(r=.80$; Harnett, Loxton, Sadler, Hides, Baldwin, 2005). The HoNOSCA has also been shown to have good concurrent validity with other measures of psychopathology (Yates, Garralda \& Higginson, 1999), with correlations over $r=.6$ or above. However, the HoNOSCA was found to have poor internal consistency in an adolescent inpatient sample $($ Cronbach alpha $=.45 ;$ Harnett, Loxton, Sadler, Hides \& Baldwin, 2005). As recovery has been shown to be inversely related to psychiatric symptoms (Corrigan et al., 1999; Resnick et al., 2004), the HoNOSCA was selected as a comparator measure to assess the concurrent validity of the ReQuest-YP. Furthermore, the HoNOSCA was routinely administered in each of the services involved in this study; therefore, the data were readily available with little burden on the services and young people to complete a further measure.

\section{Procedure}

As detailed in Figure 1, eligible and consenting participants first completed the ReQuest-YP, followed by administration of the feedback questionnaire. All young people within the participating CAMHS who were already inpatients at the beginning of data collection and met the eligibility criteria were approached to participate (T1). Furthermore, all subsequent admissions to the participating CAMHS who met the study criteria were approached within their first month of their 
admission and at the earliest most appropriate time (T1). To measure test-retest reliability, an opportunity sample of participants who completed the ReQuest-YP at T1 were approached within a two-week time frame to complete the ReQuest-YP for a second time (T2) based on their availability on a designated day within the allotted two-week time frame. To measure sensitivity to change, young people were then approached to complete the ReQuest-YP again for a second time, prior to being discharged (T3). As the HoNOSCA is routinely used in all of the participating inpatient CAMHS services, scores for this clinician-rated measure were made available to the research team with participants' consent.

[Figure 1 about here]

\section{Data analysis}

IBM SPSS Statistics Version 22 was used for all quantitative calculations. The distribution of the data was assessed using skewness, kurtosis, Z scores and histograms, which revealed the majority of the variables were not normally distributed. Consequently, non-parametric tests were used where appropriate and the median score is presented where applicable. Missing data were pro-rated with the mean for that scale where less than $10 \%$ of the scale data were missing.

Comparisons between any differences on the mean ReQuest-YP score and demographic or clinical variables were analysed using a Kruskal Wallis test and Spearman's Rank order correlation. The internal consistency reliability was calculated using Cronbach's alpha. An interclass correlation coefficient (ICC) was calculated to determine the relationship between the mean scores on the ReQuest-YP at T1, and the ReQuest-YP scores at T2 to determine the test-retest reliability, with a high correlation indicating adequate scale stability. In order to test the hypothesis 
that there would be a significant difference between scores obtained at $\mathrm{T} 1$ and discharge, a Wilcoxon Rank test was performed. To test the hypothesis that there would be a significant negative relationship between the HoNOSCA and the ReQuest-YP, a Spearman's rank correlation was performed. The face validity of the ReQuest-YP was assessed by analysing both the frequencies of the feedback questionnaire and the written feedback, which were analysed using a content analysis within a qualitative framework (Erlingsson \& Brysiewicz, 2017; Elo \& Kyngas (2008).

\section{$\underline{\text { Results }}$}

\section{Sample characteristics}

A summary of the sample characteristics is provided in Table 1. The ReQuest-YP questionnaire was completed by 65 participants within an average time frame of 24 days from the date of admission. Respondents were aged between 13 and 17 $(M=15.97, S D=1.09)$. Test-retest reliability was completed at $\mathrm{T} 2$ by 13 participants within an average time frame of 8 days. The ReQuest-YP was completed upon discharge at $\mathrm{T} 3$ by 12 participants within an average time frame of 58 days (approximately 2 months). The participants met criteria for a range of mental health diagnoses, which are presented in Table 1. All 65 young people completed the ReQuest-YP, with only six missing values across the scale at $\mathrm{T} 1$, one missing item at $\mathrm{T} 2$, and one missing item at T3. No participant had $10 \%$ or more data missing; therefore, no data were excluded from the analysis. There were no significant differences in the ReQuest-YP scores between demographic or clinical groupings.

\section{[Table 1 about here]}




\section{Descriptive statistics}

The mean, standard deviation, median and range of scores were calculated for the total score on the ReQuest-YP $(M=30.84, S D=14.6$, Median=28.00), with high scores on the ReQuest-YP indicating greater subjective recovery (90 being the highest possible score and 0 being the lowest possible score). The lowest total score in this sample was 7 and the highest score was 71 . Table 2 provides the means, standard deviation and range of scores for each item on the ReQuest-YP measure. Scores ranged from 0 to 3 on each item, which demonstrates that the whole scale on the ReQuest-YP was used and no part of the scale was redundant.

\section{[Table 2 about here]}

\section{Internal reliability}

Cronbach's alpha was calculated on the ReQuest-YP and was $\alpha=.914$, which indicates the scale has a high level of inter-item reliability. The Cronbach alphas for each item on the questionnaire if item deleted ranged from $\alpha=.907$ to $\alpha=.916$, indicating that all items were relevant. Three items had low inter-item correlation $(<.3$; question numbers 29,5 and 21). These three items were not removed because they still demonstrated high inter-item reliability $(>.9)$.

\section{Test-retest reliability}

Test-retest data were available for 13 participants across a two-week time frame, with a mean time interval of eight days. The mean ReQuest-YP score at baseline was $30.23(S D=9.87)$ and the mean at $\mathrm{T} 2$ was $31.31(S D=11.05)$. An interclass correlation coefficient was calculated which demonstrated significant agreement 
between mean scores at $\mathrm{T} 1$ and $\mathrm{T} 2, \operatorname{ICC}(2, \mathrm{k})=.910, p<.001$, reflecting excellent agreement between the two scores, indicating measure stability.

\section{Sensitivity to change}

Sensitivity to change data were available for 12 young people. The average time interval between the two administrations at baseline and at discharge was 58 days. The mean score at baseline was $29.50(S D=7.86$, Median $=31.50)$ and the mean score at discharge was $35.00(S D=10.73$, Median $=33.00)$. A Wilcoxon signed rank test indicated that the difference between the ReQuest-YP scores at T1 and T2 was significant $(\mathrm{Z}=-2.091, p=.036)$.

\section{Concurrent validity}

A Spearman's Rank-order correlation was performed to determine the relationship between HoNOSCA scores $(M=19.94, S D=5.39$, Median $=19.00)$ and the ReQuest-YP score $(M=30.52, S D=14.61$, Median $=28.00)$. No significant correlation was found between the HoNOSCA and the ReQuest YP $\left(r_{s}(65)=\right.$ $.010, p=.938)$.

\section{Feedback questionnaire}

The responses from the Likert scale questions are provided in Table 3. A qualitative exploration of the descriptive responses to the open-ended questions within the feedback questionnaire was undertaken following principles suggested by Elo and Kyngas (2008). A summary of the responses and illustrative quotations are presented in Table 4. By and large, the feedback from the young people who completed the ReQuest-YP was positive. As shown in Table 3, participants agreed that the measure was easy to use, relevant to the young person's experience and the 
questions were easy to understand. However, young people reported that some of the questions within the questionnaire were distressing or upsetting. The detailed feedback from the young people provides further, more specific information in relation to this. Illustrative quotations of the detailed feedback are presented in Table 4.

[Table 3 about here]

[Table 4 about here]

\section{Qualitative exploration of the feedback questionnaire}

In line with the feedback shown in Table 3 and Table 4, the responses overall were generally positive, with participants stating that they liked the measure. In general, participants reported that they found the measure simple, easy to understand and quick to complete. Responses appeared to indicate a consensus that this questionnaire was relevant to the participant's current situation, and the questions explored areas which the young people reported they were not routinely asked about.

However, responses indicated that some of the questions were not worded appropriately and were found to be confusing. In particular, questions such as 'I have no confidence in myself' and 'I do not know who I am anymore' were reported to be difficult to answer as they were framed negatively. Furthermore, the feedback indicated that some questions were repetitive; for example, 'I have a better understanding of my problems'; 'I understand my problems'; 'I do not understand my problems at all'. The question 'I have no life' was singled out in particular as being upsetting and a "stereotypical" question for young people. Furthermore, questions, such as 'I do not know who I am anymore', were also highlighted due to 
the ambiguity of the word 'anymore'. Several participants also suggested that they wanted to provide more information in response to some of the questions and proposed the use of some open-ended questions to allow them to expand their answers if they wished.

\section{$\underline{\text { Discussion }}$}

Measuring recovery within a child and adolescent mental health context is of increasing relevance to both clinicians and policy makers. However, to date, only one known measure has been developed to specifically assess this construct in an adolescent mental health population: The ReQuest-YP. This study aimed to evaluate the psychometric properties of the ReQuest-YP in an inpatient adolescent mental health population. The ReQuest-YP demonstrated sound psychometric properties overall. It was reported to be relevant and easy to use by young people and demonstrated measure stability and the ability to measure individual recovery related outcomes over time.

Consistent with the hypotheses, the ReQuest-YP demonstrated good reliability across both the assessment of internal consistency and the test-retest reliability. The ReQuest-YP demonstrated excellent internal consistency (George and Mallerty's, 2003), which suggests that all of the items within the measure are relevant and necessary and are measuring the construct of subjective recovery. The ReQuest-YP also demonstrated good stability in its measure of recovery over a twoweek period, which signifies good internal validity of the measure and indicates little error in the measure which provides support that the ReQuest-YP has clinical utility and that conclusions drawn from the results of this measure can be relied upon.

The results revealed that the ReQuest-YP was not significantly correlated with scores on the HoNOSCA; therefore, concurrent validity of the scale was not 
established. Although this was unexpected, the HoNOSCA is a clinician-rated tool. It is possible that the lack of agreement between the measures was in relation to a difference between the adolescent self-report and the clinician's report of the young person's difficulties. Gowers, Levine, Bailey-Rogers, Shore, and Burhouse (2002) explored the relationship between the HoNOSCA and the self-reported version of the HoNOSCA, the HoNOSCA-SR, and found that there was little agreement between the clinician reports and young person's self-reports on the measures. Furthermore, as the ReQuest YP demonstrated good reliability and an ability to detect significant change in subjective recovery, it is possible that the constructs which the HoNOSCA and the ReQust-YP were measuring were not related. As there are no other recovery measures developed for use in this population, future research evaluating the psychometric properties of the ReQuest- YP should evaluate the concurrent validity in a validated self-report measure developed for use within this population, such as, the Strength and difficulties questionnaire (SDQ; Goodman 1997).

The ReQuest-YP demonstrated it was sensitive to measuring change in subjective recovery over an average time period of approximately 2 months (58 days), with the young people rating themselves as having higher subjective recovery on the ReQuest-YP at discharge. This is consistent with the view that patients who have been assessed by clinicians as suitable to be discharged back to the community from an inpatient mental health setting would demonstrate greater levels of subjective recovery. Indeed, recovery in mental health is related to an increased control over daily life, social re-engagement and re-establishing inter personal relationships (Nelson, Lord \& Ochocka, 2001). Additionally, this finding suggests that the ReQuest-YP has some clinical utility for use an outcome measurement tool for routine outcome monitoring or to evaluate existing services. Future research will need to replicate this with larger samples and establish normative data for the 
ReQuest-YP for different populations of young people within mental services could be a useful tool for aiding a clinician's interpretation of scores on the ReQuest-YP, to establish whether any change that is made is clinically meaningful.

The findings indicated that young people were generally positive about the ReQuest-YP and demonstrated an agreement that the measure was easy to understand and complete and was relevant to adolescents within an inpatient mental health service. However, feedback also indicated that some revision to the wording of both the Likert scale response options and some of the questions is warranted because some participants reported a level of confusion around the negatively phrased items. Van Sonderen, Sanderman and Coyne (2013) found that items which were phrased negatively on questionnaires led to respondents becoming confused, inattentive and frustrated, which impacted on a participant's level of engagement with measures. In light of this, despite the sound psychometric properties found, this feedback highlights the limits to the clinical utility of the ReQuest-YP. In order for the ReQuest-YP to be clinically useful, further refinement of the ReQuest-YP items is necessary to review negatively worded items and the use of repeated questions along with refinement of the anchor point descriptions. Further evaluation of the ReQuest-YP should be undertaken once revisions have been made.

Consistent with findings in the adult literature (Luo, Harvey, Tran, Phung, Venkatesh \& Connor, 2016), the descriptive statistics indicated a difference between the mean scores obtained in this inpatient CAMHS sample on the ReQuest-YP ( $M=$ 30), and the mean score obtained in a community CAMHS sample on the ReQuestYP $(M=43)$ as reported by John et al. (2015). This provides some support that the measure is able to discriminate between different populations. However, as this was not explored within this study, this requires further assessment before conclusions can be drawn. Furthermore, in examining the descriptive statistics, the low level of 
missing data across the responses suggests the acceptability of the measure to young people.

\section{Strengths, limitations and future research recommendations}

A strength of this study was that a clinical sample derived from five inpatient child and adolescent mental health services across the Northwest of the UK was used. This provides the ability for some generalisations of the findings from this study to young people in other similar services, which supports the clinical utility of the measure.

Furthermore, a qualitative exploration of the acceptability and face validity of the ReQuest-YP was conducted, which many other studies fail to consider when developing or evaluating outcome measures (Wiering, Boer \& Delnoij, 2017) and that might increase the utility of the tool to the population (Fossey \& Harvey, 2001). With this in mind, following the feedback from young people in this study, the ReQuest-YP warrants a review of some of the questions and of the Likert scale response options, and a refinement of the ReQuest-YP to minimise a respondent's confusion and frustration. Following this, the ReQuest-YP should be further evaluated, addressing the limitations of the small sample size used in this study.

The sample size used in this study was small and therefore limits the conclusions which can be drawn, both in terms of reliability and generalisability. Access to a larger sample size would have provided the opportunity to conduct a factor analysis on the data, which would have allowed for rich information about the structural validity of the measure and provided an assessment of unidimensionality of the items on the ReQuest-YP to strengthen the internal consistency findings and mitigate the limitations of the Cronbach's alpha test. Mean imputation has limitations as a solution to missing data. In addition, we do not hold comprehensive data on the number of participants approached and who refused to complete the 
ReQuest-YP, or higher level data on the number of young people admitted to the services during the recruitment period. This would enable more exploration of the generalisability of the data and possible reasons for missingness and so future work should seek to systematically collect this data.

A further limitation of this study was that the sample was predominantly white British females. This study utilised an opportunity sample of young people who were inpatients at the time of the study and as such the demographic of the sample reflect that of the specific clinical services studied. Therefore, results must be generalised with caution to other groups.

The use of the HoNOSCA as a comparator construct also has limitations because it is unclear whether the lack of relationship between the HoNOSCA and the ReQuest-YP was due to the ReQuest-YP having poor concurrent validity, or whether the HoNOSCA was not an adequate comparator due to different classes of informants or possibly measuring a different mental health construct. Future research should explore the relationship of the ReQuest-YP with other relevant self-report measures in order to better understand the ReQuest-YP concurrent validity. It would also be informative to compare the ReQuest-YP scores to another recommended outcome measure, the Children's Global Assessment Scale (CGAS; Shaffer et al., 1983).

Furthermore, a number of other key psychometric properties were not evaluated in this study which would have strengthened the interpretation of the findings for clinical use. In particular, an assessment of the discriminant validity would have provided useful information in order to adequately determine whether the ReQuest-YP could distinguish between non-clinical and different clinical populations. Obtaining this information could be used to develop normative data and guidelines to strengthen clinical decision making. 


\section{Clinical implications}

The findings from this study indicate that the ReQuest-YP demonstrates excellent reliability, is sensitive to change, and has good face validity and acceptability for use within inpatient CAMHS, indicating its utility for routine use in inpatient CAMHS. In order for the ReQuest-YP to be utilised in the most meaningful way, it may be necessary to fully embed the ReQuest-YP into a service so that the questionnaire is regularly administered and informs treatment goals to evaluate treatment effectiveness and service outcomes. In line with recommendations, (Knaup, Koesters, Schoefer, Becker \& Puschner, 2009) the development of a mechanism within the service to feed back the results from the ReQuest-YP to young people would also prove clinically useful and enhance a recovery focused orientation to the service.

The young people's feedback indicated that some participants felt that they wanted to elaborate on some of their answers and reported the measure covered questions that they were not routinely asked. This suggests that the ReQuest-YP may provide a useful tool for clinicians to use alongside young people as a means to obtain richer, clinically relevant information about the young person to inform their understanding of the young person's difficulties, and to identify recovery-oriented goals, which are meaningful to the young person, as recommended (Department of Health, 2009).

Using the ReQuest-YP may provide the opportunity to enhance individual interventions and promote a recovery focused orientation to inpatient services, and may inform future recovery orientated service developments, in line with the Future in Mind agenda (NHS England, 2015). 


\section{Conclusion}

In summary, the ReQuest-YP demonstrates sound psychometric properties and appears to have clinical utility as a measure of subjective recovery within an inpatient adolescent mental health service. The scale is relevant and accessible to the population and has scope for further development and validation. The use of the ReQuest-YP provides the opportunity to support the notion of personal recovery, ensure young people have meaningful treatment targets and allow services to be effectively and holistically evaluated. 


\section{Declaration of conflicting interests}

None. 


\section{$\underline{\text { References }}$}

Bentley, N., Davies, J., Sellen, J., \& Maggs, R. (2017). An initial evaluation of the Global Review Form as an approach to measuring individual change. The Journal of Forensic Psychiatry \& Psychology, 28(4), 458-476.

Corrigan, P. W., Giffort, D., Rashid, F., Leary, M., \& Okeke, I. (1999). Recovery as a psychological construct. Community Mental Health Journal, 35(3), 231-239.

Davidson, L., \& Roe, D. (2007). Recovery from versus recovery in serious mental illness: One strategy for lessening confusion plaguing recovery. Journal of Mental Health, 16(4), 459-470.

Department of Health. (2002). Reforming NHS Financial Flows: Introducing Payment by Results. London: DoH.

Department of Health. 2009. Departmental Report. The Health and Personal Social Services Programmes: Retrieved from:

https://assets.publishing.service.gov.uk/government/uploads/system/uploads/attachm ent_data/file/228879/7593.pdf (Date if retrieval 13/5/2018).

Donnelly, M., Scott, D., McGilloway, S., O’Neill, T., Williams, J., \& Slade, M. (2011). Patient outcomes: What are the best methods for measuring recovery from mental illness and capturing feedback from patients in order to inform service improvement. A report commissioned by the Bamford Implementation Rapid Review Scheme.

Elo, S., \& Kyngäs, H. (2008). The qualitative content analysis process. Journal of Advanced Nursing, 62(1), 107-115.

England, N. H. S. (2015). Future in mind: Promoting, protecting and improving our children and young people's mental health and wellbeing. London: Department of Health. Retrieved from: https://assets.publishing.service.gov.uk/government/uploads/system/uploads/attachm ent_data/file/414024/Childrens_Mental_Health.pdf. Date of Retrieval: 13/04.2018.

Erlingsson, C., \& Brysiewicz, P. (2017). A hands-on guide to doing content analysis. African Journal of Emergency Medicine, 7(3), 93-99.

Fossey, E. M., \& Harvey, C. A. (2001). A conceptual review of functioning: implications for the development of consumer outcome measures. Australian and New Zealand Journal of Psychiatry, 35(1), 91-98.

Garralda, M., Rose, G., \& Dawson, R. (2008). Measuring outcomes in a child psychiatry inpatient unit. Journal of Children's Services, 3(3), 6-16.

George, D., \& Mallery, P. (2003). Reliability analysis. SPSS for Windows, step by step: a simple guide and reference, 14th edition. Boston: Allyn \& Bacon, 222-232.

Godfrey, E., Aubrey, M., Crockford, S., Haythorne, D., Kordowicz, M., \& Ashworth, M. (2019). The development and testing of PSYCHLOPS Kids. Child and Adolescent Mental Health, 24(1), 54-65.

Goodman, R. (1997). The Strength and Difficulties Questionnaire: A research note. Journal of Child Psychology and Psychiatry, 38(4), 581-586.

Gowers, S. G., Harrington, R. C., Whitton, A., Lelliott, P., Beevor, A., Wing, J., \& Jezzard, R. (1999). Brief scale for measuring the outcomes of emotional and behavioural 
disorders in children: Health of the Nation Outcome Scales for Children and Adolescents (HoNOSCA). The British Journal of Psychiatry, 174(5), 413-416.

Gowers, S., Levine, W., Bailey-Rogers, S., Shore, A., \& Burhouse, E. (2002). Use of a routine, self-report outcome measure (HoNOSCA-SR) in two adolescent mental health services. The British Journal of Psychiatry, 180(3), 266-269.

Green H, McGinnity A, Meltzer H, Ford T, Goodman R (2005). Mental health of children and young people in Great Britain, 2004. A survey carried out by the Office for National Statistics on behalf of the Department of Health and the Scottish Executive. Basingstoke: Palgrave Macmillan.

Harnett, P. H., Loxton, N. J., Sadler, T., Hides, L., \& Baldwin, A. (2005). The Health of the Nation Outcome Scales for Children and Adolescents in an adolescent in-patient sample. Australian and New Zealand Journal of Psychiatry, 39(3), 129-135.

John, M., Jeffries, F. W., Acuna-Rivera, M., Warren, F., \& Simonds, L. M. (2015). Development of measures to assess personal recovery in young people treated in specialist mental health services. Clinical Psychology \& Psychotherapy, 22(6), 513524.

Knaup, C., Koesters, M., Schoefer, D., Becker, T., \& Puschner, B. (2009). Effect of feedback of treatment outcome in specialist mental healthcare: meta-analysis. The British Journal of Psychiatry, 195(1), 15-22.

Leamy, M., Bird, V., Le Boutillier, C., Williams, J., \& Slade, M. (2011). Conceptual framework for personal recovery in mental health: systematic review and narrative synthesis. The British Journal of Psychiatry, 199(6), 445-452.

Luo, W., Harvey, R., Tran, T., Phung, D., Venkatesh, S., \& Connor, J. P. (2016). Consistency of the Health of the Nation Outcome Scales (HoNOS) at inpatient-tocommunity transition. BMJ Psychiatry 6(4).

McDougall, T., Worrall-Davies, A., Hewson, L., Richardson, G., \& Cotgrove, A. (2008). Tier 4 Child and Adolescent Mental Health Services (CAMHS)-Inpatient Care, Day Services and Alternatives: An Overview of Tier 4 CAMHS Provision in the UK. Child and Adolescent Mental Health, 13(4), 173-180.

Nelson, G. B., Lord, J., \& Ochocka, J. (2001). Shifting the paradigm in community mental health: Towards empowerment and community. University of Toronto Press.

Offord, A., Turner, H., \& Cooper, M. (2006). Adolescent inpatient treatment for anorexia nervosa: A qualitative study exploring young adults' retrospective views of treatment and discharge. European Eating Disorders Review, 14(6), 377-387

Petersen, K. S., Friis, V. S., Haxholm, B. L., Nielsen, C. V., \& Wind, G. (2015). Recovery from mental illness: a service user perspective on facilitators and barriers. Community Mental Health Journal, 51(1), 1-13.

Pitt, L., Kilbride, M., Nothard, S., Welford, M., \& Morrison, A. P. (2007). Researching recovery from psychosis: a user-led project. The Psychiatrist, 31(2), 55-60.

Resnick, S. G., Rosenheck, R. A., \& Lehman, A. F. (2004). An exploratory analysis of correlates of recovery. Psychiatric Services, 55(5), 540-547. 
Shanks, V., Williams, J., Leamy, M., Bird, V. J., Le Boutillier, C., \& Slade, M. (2013). Measures of personal recovery: a systematic review. Psychiatric Services, 64(10), 974-980.

Simonds, L. M., Pons, R. A., Stone, N. J., Warren, F., \& John, M. (2014). Adolescents with anxiety and depression: is social recovery relevant? Clinical Psychology \& Psychotherapy, 21(4), 289-298.

Slade, M., Amering, M., Farkas, M., Hamilton, B., O'Hagan, M., Panther, G., Perkins, R., Shepherd. G., \& Whitley, R. (2014). Uses and abuses of recovery: implementing recovery-oriented practices in mental health systems. World Psychiatry, 13(1), 1220.

Tew, J., Ramon, S., Slade, M., Bird, V., Melton, J., \& Le Boutillier, C. (2012). Social factors and recovery from mental health difficulties: a review of the evidence. The British Journal of Social Work, 42(3), 443-460.

Van Sonderen, E., Sanderman, R., \& Coyne, J. C. (2013). Correction: Ineffectiveness of reverse wording of questionnaire items: Let's learn from cows in the rain. PloS One, $8(9)$.

Wiering, B., Boer, D., \& Delnoij, D. (2017). Patient involvement in the development of patient reported outcome measures: a scoping review. Health Expectations, 20(1), 11-23.

Wolpert, M., Harris, R., Jones, M., Hodges, S., Fuggle, P., James, R., \& Fonagy, P. (2014). THRIVE: the AFC-Tavistock model for CAMHS. Retrieved from: http://www.implementingthrive.org/wp-content/uploads/2016/03/Thrive.pdf (Date of retrieval 15/04/2018).

Yates, P., Garralda, M. E., \& Higginson, I. (1999). Paddington Complexity Scale and Health of the Nation Outcome Scales for children and adolescents. The British Journal of Psychiatry, 174(5), 417-423. 
Table 1: Observed frequencies for the characteristics of the sample.

\begin{tabular}{lll}
\hline & Sample characteristic & N (\%) \\
\hline Gender & Male & $11(16.9 \%)$ \\
& Female & $52(80 \%)$ \\
& Transgender & $2(3.1 \%)$ \\
& White British & $58(89.2 \%)$ \\
& British Asian & $4(6.2 \%)$ \\
& African- Caribbean & $1(1.5 \%)$ \\
& Mixed African- Caribbean / & $1(1.5 \%)$ \\
& British Pakistani & $1(1.5 \%)$ \\
& Service 1 & $4(6.2 \%)$ \\
& Service 2 & $16(24.6 \%)$ \\
& Service 3 & $13(20 \%)$ \\
& Service 4 & $6(9.2 \%)$ \\
& Service 5 & $26(40 \%)$ \\
& None specified & $5(7.7 \%)$ \\
& Psychosis & $5(7.7 \%)$ \\
& OCD & $1(1.5 \%)$ \\
& Depression & $8(12.3 \%)$ \\
& Anxiety & $3(4.6 \%)$ \\
& PTSD & $4(6.2 \%)$ \\
& Adjustment disorder & $15(23.1 \%)$ \\
& ASC & $3(4.6 \%)$ \\
& Anorexia & $13(20 \%)$ \\
\hline & &
\end{tabular}


Table 2: The means, standard deviations and range for the scores on each item of the ReQuest YP ( $n=65)$

\begin{tabular}{|c|c|c|c|c|}
\hline Item & M & SD & MIN & MAX \\
\hline I enjoy being with my friends & 1.80 & .77 & 0 & 3 \\
\hline Talking about my problems makes me feel better & 1.90 & .72 & 0 & 3 \\
\hline My problems will always ruin my life* & .86 & .89 & 0 & 3 \\
\hline I do not see my friends because of how I feel* & 1.22 & 1.04 & 0 & 3 \\
\hline $\begin{array}{l}\text { Knowing that there are other people my age with } \\
\text { similar problems makes me feel better }\end{array}$ & 1.28 & 1.01 & 0 & 3 \\
\hline I am too frightened to do anything* & 1.66 & .96 & 0 & 3 \\
\hline I can see how my life could be better & .98 & .54 & 0 & 3 \\
\hline I do not feel alone anymore & .82 & .92 & 0 & 3 \\
\hline I have a better understanding of my problems & 1.11 & .89 & 0 & 3 \\
\hline I have no life* & 1.18 & 1.08 & 0 & 3 \\
\hline $\begin{array}{l}\text { My problems are not affecting me as badly as } \\
\text { before }\end{array}$ & .82 & .88 & 0 & 3 \\
\hline I have abilities and talents & .65 & .80 & 0 & 3 \\
\hline I find ways to be with my friends & .98 & .84 & 0 & 3 \\
\hline I feel quite alone because nobody understands me* & 1.18 & .95 & 0 & 3 \\
\hline I cope with my problems much better than before & .91 & .84 & 0 & 3 \\
\hline I do not know who I am any more* & 1.08 & 1.95 & 0 & 3 \\
\hline I wish I could be like other people my age* & .89 & 1.04 & 0 & 3 \\
\hline I am hopeful about my future & .72 & .98 & 0 & 3 \\
\hline I look for people to talk to about my problems & .98 & .81 & 0 & 3 \\
\hline I believe in myself & .46 & .85 & 0 & 3 \\
\hline I am not different to other people my age & .72 & .91 & 0 & 3 \\
\hline I understand my problems & 1.26 & .89 & 0 & 3 \\
\hline I have no confidence in myself* & .92 & .94 & 0 & 3 \\
\hline I do not understand my problems at all* & 1.71 & .93 & 0 & 3 \\
\hline I have learnt ways to manage my problems & .98 & .79 & 0 & 3 \\
\hline I like who I am & .46 & .85 & 0 & 3 \\
\hline People around me understand and can help me & 1.12 & .82 & 0 & 3 \\
\hline I try my hardest and, if it fails, I try again & 1.03 & 1.00 & 0 & 3 \\
\hline I try not to share my problems with anybody* & 1.18 & .85 & 0 & 3 \\
\hline I can enjoy my life despite having my problems & 0.72 & .86 & 0 & 3 \\
\hline
\end{tabular}

*Item is reverse scored 
Table 3: The frequency of participants who agreed with each Likert scale dimension within the feedback questionnaire

\begin{tabular}{|c|c|c|c|c|c|}
\hline & $\begin{array}{l}\text { Strongly } \\
\text { disagree }\end{array}$ & Disagree & $\begin{array}{l}\text { Neither } \\
\text { disagree } \\
\text { or agree }\end{array}$ & Agree & $\begin{array}{l}\text { Strongly } \\
\text { agree }\end{array}$ \\
\hline The ReQuest-YP was easy to complete & 0 & 3 & 5 & 37 & 12 \\
\hline The questions were easy to understand & 2 & 11 & 0 & 29 & 15 \\
\hline $\begin{array}{l}\text { The ReQuest-YP measure questions were } \\
\text { relevant to my current experience }\end{array}$ & 0 & 1 & 13 & 32 & 11 \\
\hline $\begin{array}{l}\text { The time taken to complete the measure was } \\
\text { about right }\end{array}$ & 1 & 1 & 0 & 31 & 15 \\
\hline $\begin{array}{l}\text { The ReQuest-YP questionnaire asked } \\
\text { questions which are important to me at this } \\
\text { time }\end{array}$ & 0 & 2 & 16 & 28 & 11 \\
\hline $\begin{array}{l}\text { The ReQuest-YP asked questions which I } \\
\text { found distressing/upsetting }\end{array}$ & 17 & 18 & 15 & 6 & 1 \\
\hline $\begin{array}{l}\text { I found the wording of the questions on the } \\
\text { ReQuest-YP measure appropriate }\end{array}$ & 1 & 5 & 9 & 29 & 13 \\
\hline $\begin{array}{l}\text { I think that the ReQuest-YP is a good way } \\
\text { for the staff on the unit to understand me } \\
\text { better }\end{array}$ & 3 & 4 & 17 & 21 & 12 \\
\hline $\begin{array}{l}\text { I found it easy to understand how to record } \\
\text { my answers }\end{array}$ & 0 & 2 & 5 & 28 & 22 \\
\hline
\end{tabular}

Results presented in bold indicate the most frequent rating on that item 
Table 4: Participant Feedback $(n=57)$

Nature of feedback

\begin{tabular}{|l}
\hline Ease of use \\
\hline Relevance of the \\
questionnaire
\end{tabular}

\section{Wording of questions}

\section{The rating scale anchor points}

\section{Illustrative Quotation}

"Simple and easy to fill in".

"I like the format, just tick questions, simple layout".

"I thought it was a good questionnaire, and felt like it was the right number of questions".

"The wording of the questions was easy to understand".

"The rating system was easy to use".

"Simple statements, easy and simple to complete and only took 5 minutes".

"It gave me another opportunity to express my thoughts and feelings and is another way of understanding my thoughts to help my treatment"

"It was a way of considering concepts of life not previously explored".

"The questions were different and focus on subjects that don't always get focused on. It's nice to know that somebody is thinking about that".

"It highlighted multiple issues I feel relate to my own self and my experience".

"Simple uses of double negatives e.g. 'I have no confidence in myself' makes the answers confusing".

"The wording was somewhat ambiguous and at times misleading, such as asking questions that switch between the statements 'I do' and 'I do not' and one of the questions 'I have no life' seems more cliché than it does of use".

"Some of the questions were double negative so made it hard to answer".

"The questions seemed a little repetitive like they were just re worded and confused me a little and it asked the same questions a few times"

"Questions with "I am not" in are harder to understand and unnecessary. Instead of "I do not know who I am anymore, ask "I know who I am". Also "anymore" is unnecessary and confusing".

"The choice 0-3 was somewhat confusing at times when you get a negative question then positive it's hard to know which one to circle".

"The wording of some of the questions is hard to match up with the scale".

"Some of the statements were hard to fit into the 'not at all, a little, a lot, completely labels".

"The question about 'I have a life' is quite subjective and difficult to answer".

Disliked questions

"The questions through no fault of their own were quite stereotypical and naive 'I have no life' 'no one understands me', I found difficult to answer".

"I have no life question could be upsetting". 